\title{
Numerical Study of the Seasonal Variation of Elevated Dust Aerosols from the Taklimakan Desert
}

\author{
Taichu Y. Tanaka \\ Meteorological Research Institute, Tsukuba, Japan
}

\begin{abstract}
Mineral dust aerosols from the Taklimakan desert can be elevated to high altitude and transported long distances, thus affecting the Earth's climate. A numerical simulation was conducted to elucidate the seasonal characteristics of dust elevated from the Taklimakan desert. The global land area was divided into the western (including the Taklimakan desert) and eastern region of China and Mongolia (including the Gobi desert), and the other regions so that the relative contributions of mineral dust from the Taklimakan and Gobi deserts to the global dust budget could be identified. The lifetime of the simulated dust aerosols from the Taklimakan desert (2.1 days) was longer than that of aerosols from the Gobi Desert (1.5 days). Simulated dust emission increased in March, peaked in April to May, and decreased from June to September, which is a seasonal variation pattern consistent with the observed Taklimakan dust storm frequency. The simulated Taklimakan dust concentration in the upper troposphere was higher than that of the Gobi dust, suggesting that Taklimakan dust tends to be transported to higher altitudes. It is also suggested that the Taklimakan dust is trapped in the Asian summer anticyclone and partly contributes to the formation of the Asian tropopause aerosol layer during summer.
\end{abstract}

\section{Introduction}

Mineral dust has been recognized as an important component of the Earth's climate system because it affects the radiation budget in several ways: it disturbs the atmospheric energy budget directly by scattering and absorbing the atmospheric radiation (e.g., Sokolik and Toon 1996) and indirectly by acting as cloud condensation nuclei and ice nuclei; it may also impact the carbon cycle and atmospheric $\mathrm{CO}_{2}$ by depositing iron as a nutrient to the oceanic phytoplankton (e.g., Jickells et al. 2005).

Asian dust is transported long distances. Previous studies have reported that Asian dust particles were found in an ice core in Greenland (e.g., Biscaye et al. 1997), and they are transported in the full circle of the Northern Hemisphere according to the analysis of observations by the satellite-borne Cloud-Aerosol Lidar with Orthogonal Polarization (CALIOP) and to numerical simulations by global aerosol model (Uno et al. 2009). The observed Asian dust shows a two-layer vertical structure, i.e., the dust from the Taklimakan desert tends to be transported to the upper troposphere, and dust from the eastern regions of China and Mongolia, including the Gobi desert, is transported in the lower troposphere (e.g., Iwasaka et al. 1983). The uplifted Taklimakan dust can form a very thin, veil-structured plume, as was reported by Yumimoto et al. (2009). The Asian dust events mainly occur in spring, but the Taklimakan dust events have also been observed in summer (Kurosaki and Mikami 2002; Liu et al. 2008; Yumimoto et al. 2010). These studies suggest that Asian dust aerosols, especially those from the Taklimakan desert, can be transported to the upper troposphere and over long distances and are therefore important due to their potential to act as ice nuclei in the upper troposphere. However, most of the previous studies are case studies of single

Corresponding author: Taichu Y. Tanaka, Meteorologocal Research Institute, 1-1 Nagamine, Tsukuba 305-0052, Japan. E-mail: yatanaka@mri-jma. go.jp. (C)2012, the Meteorological Society of Japan. events. Consequently, the seasonal characteristics of the uplifted Taklimakan dust are not well understood, and it is difficult to distinguish the Taklimakan dust from dust originating from other regions.

In this study, a numerical simulation of the transport of dust aerosols with a global aerosol model was conducted to elucidate the long-range transport of dust aerosols from the Taklimakan desert. The seasonality of the simulated frequency of the Taklimakan dust aerosols was investigated to examine the characteristics of the Taklimakan desert in comparison with dust from the Gobi desert.

\section{Model description}

The numerical model used for this study was the Model of Aerosol Species IN the Global AtmospheRe (MASINGAR) (Tanaka and Chiba 2005), which is a global aerosol model that is online coupled with a general circulation model, MRI/JMA 98 GCM (Shibata et al. 1999). The model includes advective transport, vertical eddy diffusion, moist convective transport, gravitational settling and the dry and wet scavenging of aerosols. The advective transport is calculated using a three-dimensional semi-Lagrangian advection scheme. The eddy diffusivity for vertical diffusion is calculated using the level-2 turbulence closure scheme of Mellor and Yamada (1974). The moist convective transport is calculated using the updraft mass flux of the ArakawaSchubert moist convection scheme (Arakawa and Schubert 1974) as in the MRI/JMA 98 GCM. Dry deposition process is parameterized with the resistance-in-series approach (Wesely and Hicks 1977), which includes turbulent impaction and gravitational settling. In-cloud scavenging is calculated using the scheme of Giorgi and Chameides (1986), and below-cloud scavenging is calculated based on the theory of Slinn (1984). Both the dry and wet deposition processes in the model are particle-size dependent.

The dust emission flux is calculated as a function of the friction velocity, based on the saltation-bombardment theory. The threshold friction velocity of the mobilization of soil particles is calculated with the formula of Shao and $\mathrm{Lu}$ (2000) with the soil moisture dependence of Fécan et al. (1999). The horizontal saltation flux of sand particles is calculated with the scheme of Owen (1964), and the vertical dust flux is calculated based on the energy-based dust emission scheme proposed by Shao et al. (1996). The dust aerosol is divided into discrete size-classes from 0.2 to $20 \mu \mathrm{m}$ in diameter, which are transported independently and assumed to be non-interacting. For the sake of reducing computational costs, the dust aerosol was divided into 6 size classes, whereas the original version considered 10 size classes. Tanaka and Chiba (2005) presented a detailed description of the dust aerosol model and its validations with available observations. This model has been used to study the long-range transport of dust aerosols (Tanaka and Chiba 2006).

Dust source areas are determined by the surface characteristics. The water surface and the ground with the land-use type of broadleaf/coniferous evergreen forest, or the soil type of lithosol are omitted from the dust source region. For the other regions, dust source area is decreased with the snow covered area and the leaf area index designated by the land surface model of the GCM.

Because the Taklimakan desert is surrounded by the complex terrains, simulated dust emission and transport from there are highly sensitive to the grid resolution, and models with coarse 
horizontal resolutions cannot reproduce the dust storms in the Taklimakan desert (Tanaka and Chiba 2006). To represent the topography as realistic as possible for the global simulation, high resolution version of the model with grid resolutions of T106 Gaussian horizontal grid (approximately $1.125^{\circ} \times 1.125^{\circ}$ ) with 30 vertical layers (from the ground surface to a height of $0.4 \mathrm{hPa}$ ) was used. The horizontal wind fields were assimilated with the six-hourly data of the global analysis of Japan Meteorological Agency (GANAL) to obtain a realistic atmospheric field. The sea surface temperature and sea ice data were prescribed by the monthly mean HadISST v1.1 data (Rayner et al. 2003). We performed a simulation from 1 October 2005 to 31 December 2010 with zero-dust initial condition, and the years 2006 to 2010 were analyzed.

To identify the relative contributions of mineral dust from the Taklimakan and Gobi deserts to the global dust budget, the global land area was divided into three potential dust source regions. In this study, the Chinese and Mongolian region west of $95^{\circ} \mathrm{E}$ where the Taklimakan desert is included, is denoted as "TAKLIMAKAN", and the Chinese and Mongolian region east of $95^{\circ} \mathrm{E}$ where the Gobi desert is included, is denoted as "GOBI." All other regions are denoted as "OTHER". The borders of the source regions are designated in Fig. 1. Dust emission fluxes from the different source regions were assigned to separate tracers and were transported independently and simultaneously. This treatment enabled us to evaluate dust emission, concentration, and deposition for each source region independently.

Parameterization of the moist convective transport is an important process to uplift the aerosols to the upper troposphere but also a major source of uncertainty in the chemical transport models (e.g., Mahowald et al. 1995). To elucidate the effect of vertical transport by moist convection, a sensitivity experiment for one year (2007) was performed. In this sensitivity experiment, moist convective transport parameterization with the updraft mass flux was switched off, while the wet deposition with convective precipitation is effective.

\section{Results and discussion}

\subsection{Annual and seasonal global dust budgets}

The annually averaged distributions of simulated dust emissions from the TAKLIMAKAN and GOBI regions are illustrated in Fig. 1, and the simulated annually averaged dust budgets of the regions are listed in Table 1 (see also Fig. S1 in the Supplement for the global distribution of the dust emission and loading).

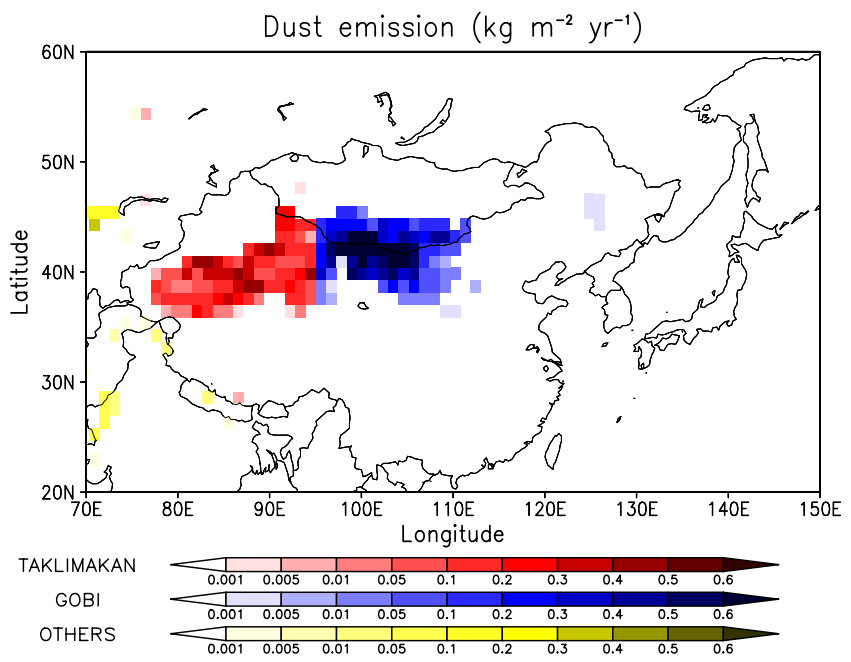

Fig. 1. Simulated five-year annually averaged dust emission flux from the East Asian dust source regions. Red: TAKLIMAKAN region (west of $95^{\circ} \mathrm{E}$ in China and Mongolia), Blue: GOBI region (east of $95^{\circ} \mathrm{E}$ in China and Mongolia), Yellow: OTHER regions. The unit is $\mathrm{kg} \mathrm{m}^{-2} \mathrm{yr}^{-1}$.
Table 1. Annual averaged dust budgets from TAKLIMAKAN (western than $95^{\circ} \mathrm{E}$ of China and Mongolia), GOBI (eastern of $95^{\circ} \mathrm{E}$ of China and Mongolia), and the OTHER regions. The values are the average of fiveyear simulation.

\begin{tabular}{lccc}
\hline & $\begin{array}{c}\text { Dust emission } \\
\left(\mathrm{Tg} \mathrm{yr}^{-1}\right)\end{array}$ & $\begin{array}{c}\text { Global dust loading } \\
(\mathrm{Tg})\end{array}$ & $\begin{array}{c}\text { Lifetime } \\
(\text { days })\end{array}$ \\
\hline TAKLIMAKAN & 185 & 1.03 & 2.1 \\
GOBI & 321 & 1.24 & 1.5 \\
OTHER & 1783 & 13.2 & 2.7 \\
\hline
\end{tabular}

The annual dust emissions from the TAKLIMAKAN, GOBI and other regions are $185 \mathrm{Tg}, 321 \mathrm{Tg}$ and $1783 \mathrm{Tg}$, respectively. The lifetime of dust particles from the TAKLIMAKAN (2.1 days) is longer than that of the GOBI (1.5 days). The difference in the lifetime of dust particles may be due to the difference of the vertical extent of the upward transport or the probability of removal by precipitation. Dust particles from the other regions have a longer lifetime (2.7 days) than those from the two East Asian dust source regions, most likely because the East Asian dust aerosols frequently encounter cloud cover (Prospero et al. 2002) and are deposited by precipitation more rapidly than in the other regions.

Figure 2 displays the simulated average seasonal variation of the emission of dust from the TAKLIMAKAN region. The dust emission activity increases in March, reaches a maximum in April to May and decreases during June to September. The seasonal variation pattern of dust emission is consistent with the observed pattern of dust storm frequency in Taklimakan (Prospero et al. 2002; Kurosaki and Mikami, 2002).

\subsection{Vertical structures}

Figure 3 shows the daily global mean concentration of dust aerosols originating from the TAKLIMAKAN and GOBI at the upper troposphere $(100 \mathrm{hPa})$, middle troposphere $(500 \mathrm{hPa})$, and near-ground level. At the ground level, the dust from the GOBI shows a higher concentration than that from the TAKLIMAKAN (Fig. 3c). However, the concentration of the TAKLIMAKAN dust is as high as that of the GOBI dust in the middle troposphere (Fig. $3 b)$. At the upper troposphere, the dust from the TAKLIMAKAN shows a higher concentration than that from the GOBI (Fig. 3a). Figure 4 displays monthly mean vertical profiles of the TAKLIMAKAN and GOBI dust concentration averaged over northwestern Pacific $\left(20^{\circ} \mathrm{N}-40^{\circ} \mathrm{N}, 150^{\circ} \mathrm{E}-170^{\circ} \mathrm{E}\right)$. Over approximately 500 $\mathrm{hPa}$, the concentration of the TAKLIMAKAN dust is apparently higher than that of the GOBI dust, which suggests that the dust from the Taklimakan desert tends to be elevated to a higher layer than that from the Gobi desert.

As shown in Figs. $3 a-3 c$, the dust aerosols from both the TAKLIMAKAN and GOBI are highly intermittently transported

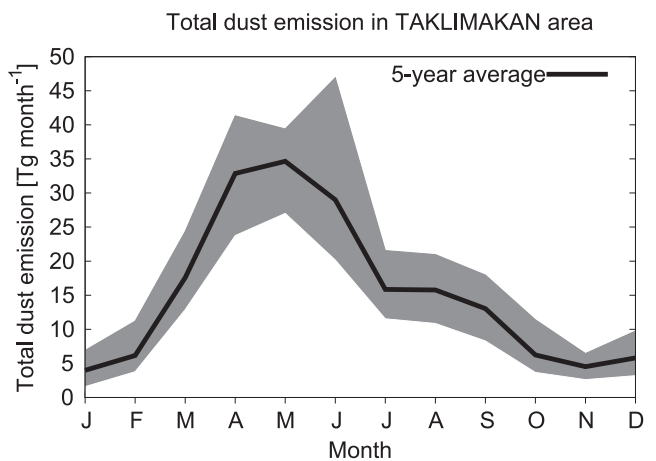

Fig. 2. Simulated seasonal variation of monthly total dust emission from TAKLIMAKAN region. Solid line shows the five-year average monthly total emission, and gray shade denotes the minimum and maximum of the monthly total emissions in the five-year experiment. The unit is $\mathrm{Tg}$ month $^{-1}$. 


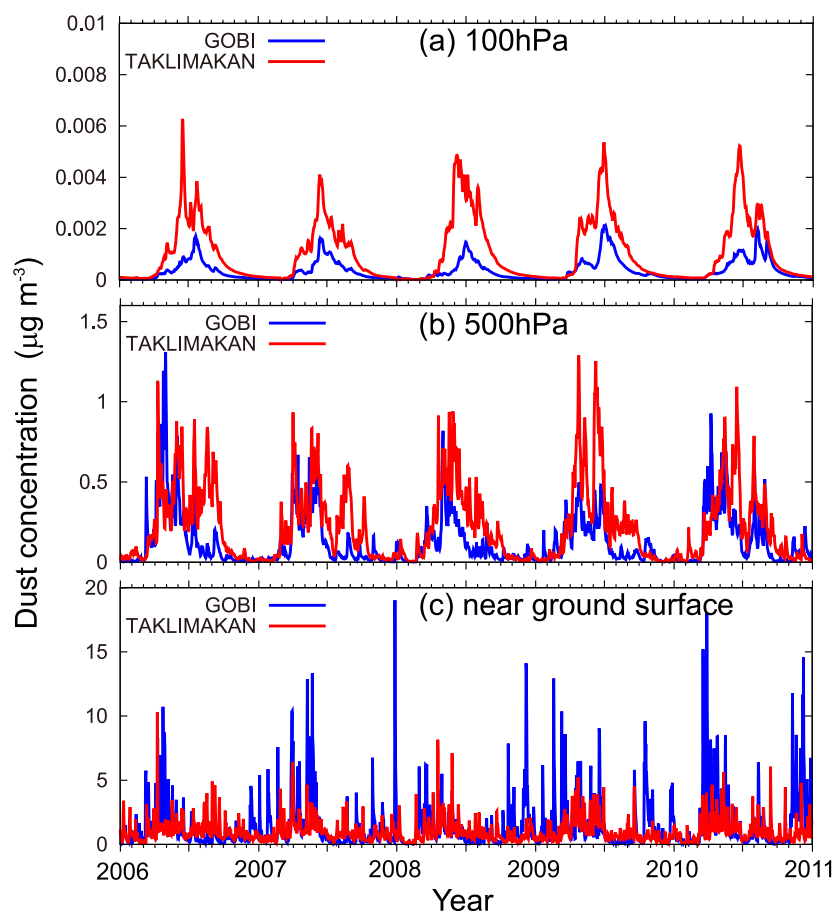

Fig. 3. Time series of the global average concentration of dust aerosol from the TAKLIMAKAN desert (red) and the GOBI (blue) at (a) $100 \mathrm{hPa}$, (b) $500 \mathrm{hPa}$, and (c) near the ground surface. The unit is $\mu \mathrm{g} \mathrm{m}^{-3}$.

to the upper troposphere from March to September. From October to February, the concentrations of dust aerosols from both deserts are not high, even though the concentrations at the ground level reach several hundred $\mu \mathrm{g} \mathrm{m}^{-3}$. In this simulation, the transport of TAKLIMAKAN dust to the upper troposphere occurred ap- proximately 12 times per year. The simulated results suggest that Taklimakan dust is frequently elevated to the upper troposphere.

\subsection{Role of moist convective transport}

Figure 5 shows the time series of simulated TAKLIMAKAN dust concentrations with and without moist convective transport. Under $500 \mathrm{hPa}$, the difference of dust concentrations with and without the convective transport process is small (Fig. 5c). Figure 5 indicates that higher altitudes result in greater differences in dust concentration with or without convective transport. The difference in dust concentration is greater in summer than in spring, which may reflect the seasonal difference of convective activity. The simulated results suggest that the vertical transport of dust from the Taklimakan desert mainly occurred by large-scale advection from spring to early summer, and that the moist convective transport enhances the elevation of dust to the upper troposphere.

\subsection{Seasonal variation of the horizontal distribution over the upper troposphere}

Figure 6 shows the horizontal distribution of simulated dust originating from the TAKLIMAKAN region on the upper troposphere $(100 \mathrm{hPa})$ from spring to summer in the Northern Hemisphere. From April to May, the TAKLIMAKAN dust concentrations are high over the Pacific and Atlantic oceans, which suggests that the Taklimakan dust is transported by the westerly wind and is gradually uplifted to the upper troposphere over the ocean. In June, the TAKLIMAKAN dust concentration is very high, not only over the Pacific Ocean but also over the Himalayas, which coincides with the location of the Asian summer monsoon anticyclone. During the summer, the TAKLIMAKAN dust has its peak concentration over the Asian summer anticyclone (approximately $20^{\circ} \mathrm{N}-40^{\circ} \mathrm{N}, 60^{\circ} \mathrm{E}-120^{\circ} \mathrm{E}$ ), and also during this season, the concentration of the TAKLIMAKAN dust is higher than that from the GOBI and the other dust source regions (see Supplement Fig. S2).

Observational studies have reported that several trace substances were found to have maxima or minima in the Asian summer monsoon anticyclone in the upper troposphere-lower stratosphere (UTLS) in the Northern Hemisphere summer. Park (a) March

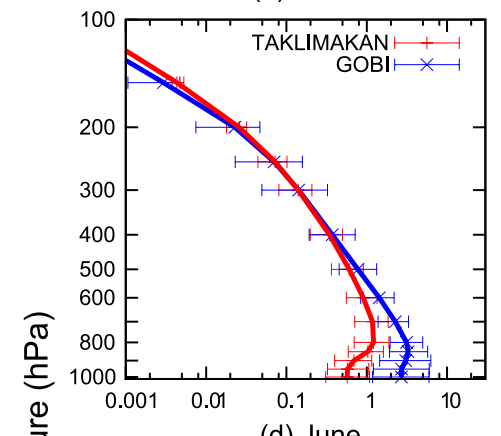

(d) June

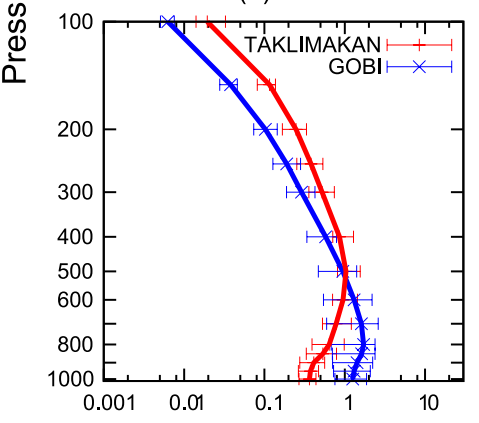

(b) April

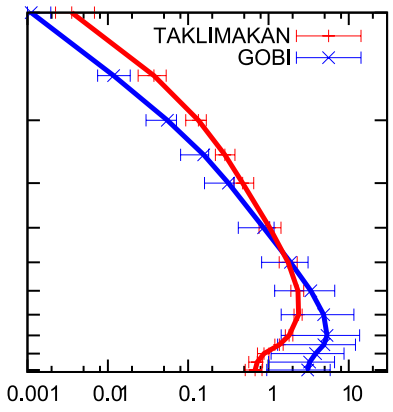

(e) July

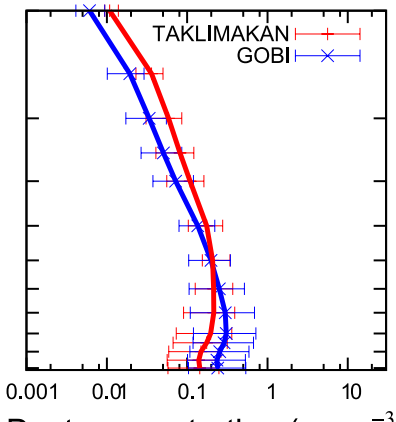

(c) May

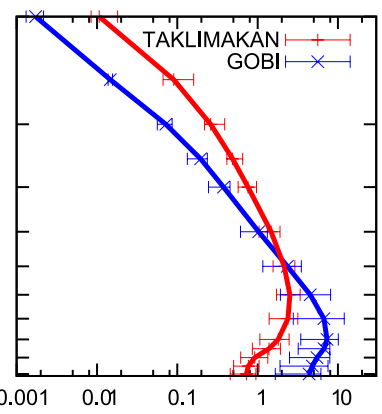

(f) August

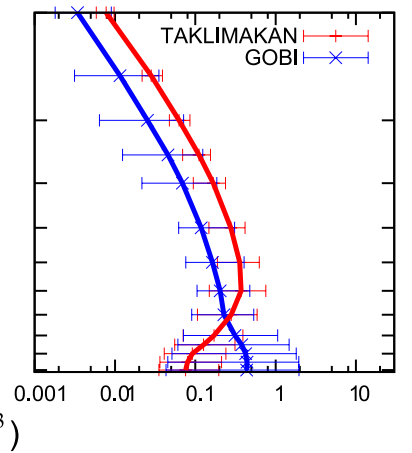

Fig. 4. Vertical profiles of the monthly mean concentrations of dust aerosol from TAKLIMAKAN and GOBI regions averaged over northeastern Pacific $\left(20^{\circ} \mathrm{N}-40^{\circ} \mathrm{N}, 150^{\circ} \mathrm{E}-170^{\circ} \mathrm{E}\right)$. (a) March, (b) April, (c) May, (d) June, (e) July, and (f) August. The error bars denote the minimum and maximum of the monthly mean concentrations in the five-year experiment. The unit is $\mu \mathrm{g} \mathrm{m}^{-3}$. 

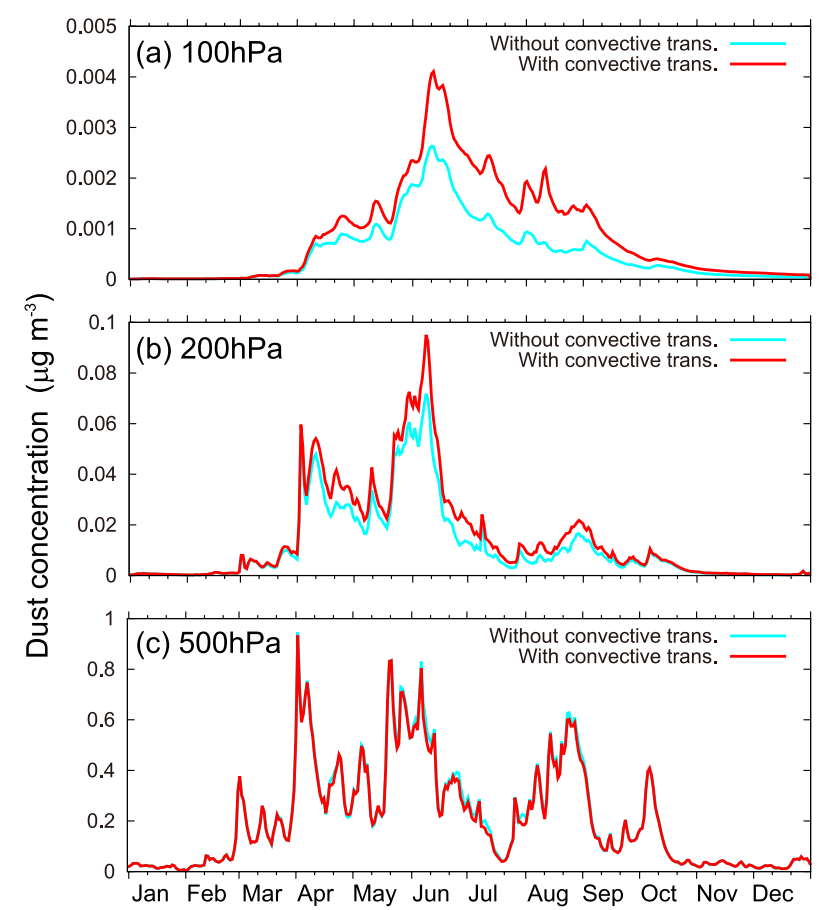

Fig. 5. Time series of the daily global average concentration of dust aerosol from the TAKLIMAKAN with (red) and without (cyan) the convective transport process. (a) $100 \mathrm{hPa}$, (b) $200 \mathrm{hPa}$, and (c) $500 \mathrm{hPa}$. Red and green lines indicate the dust concentration with and without the convective transport process, respectively. The unit is $\mu \mathrm{g} \mathrm{m}^{-3}$.

et al. (2007) showed the distributions of persistent maxima in CO and minima in ozone in the anticyclone using the Aura Microwave Limb Sounder, and they discussed its transport by convection associated with the Asian monsoon, which was clarified by Randel and Park (2006). Vernier et al. (2011) reported that a persistent aerosol layer was found to be confined within the anticyclone from June to August by satellite-borne lidar (CALIOP) observation, and they called it the Asian tropopause aerosol layer (ATAL). The ATAL extended from the eastern Mediterranean to western China and vertically from 13 to $18 \mathrm{~km}$. The particles in the ATAL are considered spherical because the depolarization of ATAL is small
(5\%). However, Vernier et al. (2011) suggested that these particles could be very small mineral dust particles. The result of our study suggests that the Taklimakan dust is transported to the upper troposphere, is confined within the Asian summer anticyclone, and may contribute to some extent to the formation of ATAL.

\section{Conclusions}

In this study, a numerical simulation using a global aerosol model was conducted to investigate the characteristics of the vertical transport of dust aerosols from the Taklimakan desert. Dust aerosols from the TAKLIMAKAN region are vertically transported to the upper troposphere from March to September. The vertical transport of the dust occurred intermittently and frequently, approximately 12 times per year. At the upper troposphere, the simulated TAKLIMAKAN dust concentration was higher than the GOBI dust concentration. This result suggests that the dust from the Taklimakan desert tends to be elevated to a higher layer than that from the Gobi desert, which forms a multi-layered vertical structure of dust aerosol.

A comparison of the dust concentration with and without convective transport suggests that the simulated dust from the Taklimakan desert was mainly transported by large-scale advection from spring to early summer, and that the moist convective transport enhanced the elevation of dust to the upper troposphere in summer. The results suggest that the elevated dust transport events are not special cases and that the Taklimakan desert provides dust aerosols intermittently and frequently to the upper troposphere. It is also suggested that the Taklimakan dust is trapped in the Asian summer anticyclone and partly contributes to the formation of the Asian tropopause aerosol layer.

Uncertainties remain in the simulated results. The model's grid resolution of approximately $1.125^{\circ}$ may not be sufficient to express the local circulation caused by the steep bounding topography around the Taklimakan desert, even though it is quite high for the global aerosol model. Because of the limitation of the model's resolution, the dust emission mechanism and the regional inhomogeneity of surface properties may not be sufficiently expressed. The convective transport process is regarded as the primary source of uncertainty in the atmospheric transport process. The results of this study are based only on a five-year simulation, which may not be sufficient to obtain the climatological state, for which more long-term integrations may be necessary. It is also necessary to investigate the year-to-year variability of the dust. Future research should include statistical validations of the elevat- (a)

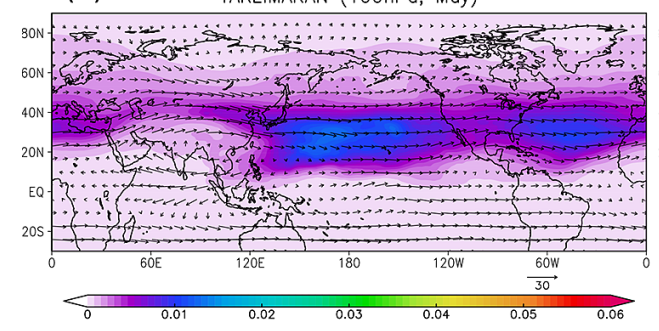

(c)

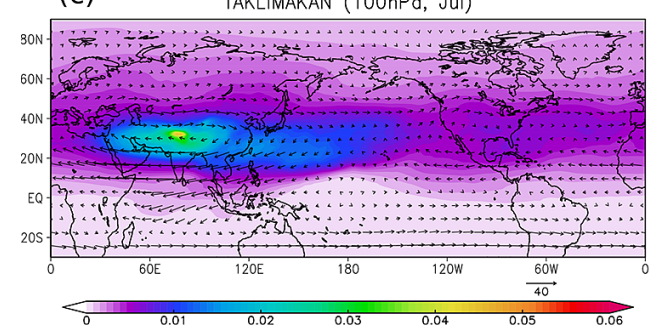

(b)

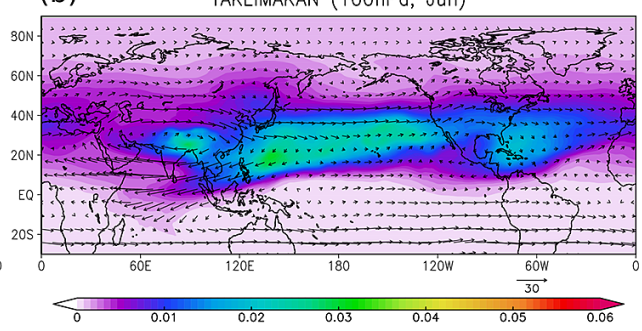

(d)

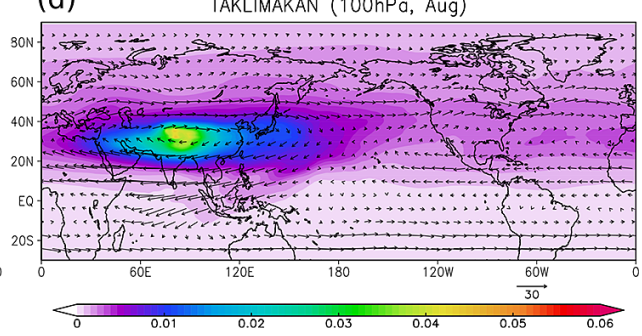

Fig. 6. Horizontal distribution of the averaged dust concentration at $100 \mathrm{hPa}$ in (a) May, (b) June, (c) July, and (d) August from the TAKLIMAKAN region. Horizontal wind fields are shown as vectors. The unit of the dust concentration is $\mu \mathrm{g} \mathrm{m}^{-3}$. 
ed dust by available observations, such as from the satellite-borne lidar CALIOP, and by estimations of the climatic roles of the elevated dust aerosols, which include direct radiative perturbation and potential roles as cloud condensation nuclei and ice nuclei.

\section{Acknowledgements}

The author would like to thank Prof. Kenji Kai and Prof. Tetsuya Takemi for valuable discussions and comments for this study. This research was partially supported by the Ministry of Education, Science, Sports and Culture, Grant-in-Aid for Scientific Research (No. 20403008).

\section{Supplement}

Figure S1. Global distribution of the annually averaged (a) simulated dust emission flux and (b) simulated dust loading.

Figure S2. Seasonal variation of the horizontal distribution of the monthly averaged dust concentration at $100 \mathrm{hPa}$ from TAKLIMAKAN (western than $95^{\circ} \mathrm{E}$ of China and Mongolia), GOBI (eastern of $95^{\circ} \mathrm{E}$ of China and Mongolia), and the other regions.

\section{References}

Arakawa, A., and W. H. Schubert, 1974: Interaction of a cumulus ensemble with the large-scale environment, part I. J. Atmos. Sci., 31, 674-701.

Biscaye, P. E., F. Grousset, M. Revel, S. Van der Gaast, G. Zielinski, A. Vaars, and G. Kukla, 1997: Asian provenance of glacial dust (stage 2) in the Greenland Ice Sheet Project 2 Ice Core, Summit, Greenland. J. Geophys. Res., 102, C12, doi:10.1029/97JC01249. 26765-26781.

Fécan, F., B. Marticorena, and G. Bergametti, 1999: Parameterization of the increase of the aeolian erosion threshold wind friction velocity due to soil moisture for arid and semi-arid areas. Annales Geophysicae, 17, 149-157.

Giorgi, F., and W. L. Chameides, 1986: Rainout lifetimes of highly soluble aerosols and gases as inferred from simulations with a general circulation model. J. Geophys. Res., 91, 1436714376.

Iwasaka, Y., H. Minoura, and K. Nagaya, 1983: The transport and spatial scale of Asian dust-storm clouds: a case study of the dust-storm event of April 1979. Tellus, 35B, 189-196.

Jickells, T. D., Z. S. An, K. K. Andersen, A. R. Baker, G. Bergametti, N. Brooks, J. J. Cao, P. W. Boyd, R. A. Duce, K. A. Hunter, H. Kawahata, N. Kubilay, J. laRoche, P. S. Liss, N. Mahowald, J. M. Prospero, A. J. Ridgwell, I. Tegen, and R. Torres, 2005: Global iron connections between desert dust, ocean biogeochemistry, and climate. Science, 308, 67-71. doi:10.1126/science.1105959.

Kurosaki, Y., and M. Mikami, 2002: Seasonal and regional characteristics of dust event in the Taklimakan Desert. J. Arid Land Studies, 11, 245-252.

Liu, Z., D. Liu, J. Huang, M. Vaughan, I. Uno, N. Sugimoto, C. Kittaka, C. Trepte, Z. Wang, C. Hostetler, and D. Winker, 2008: Air-borne dust distributions over the Tibetan Plateau and surrounding areas derived from the first year of CALIPSO lidar observations. Atmos. Chem. Phys., 8, 5045-5060.

Mahowald, N. M., P. Rasch, and R. G. Prinn, 1995: Cumulus parameterizations in chemical transport models. J. Geophys. Res., 100, 26173-26189.

Mellor, G. L., and T. Yamada, 1974: A hierarchy of turbulence closure models for planetary boundary layers. J. Atmos. Sci., 31, 1791-1806.

Owen, P. R., 1964: Saltation of uniform grains in air. J. Fluid. Mech., 20, 225-242.
Park, M., W. J. Randel, A. Gettelman, S. T. Massie, and J. H. Jiang, 2007: Transport above the Asian summer monsoon anticyclone inferred from Aura Microwave Limb Sounder tracers. J. Geophys. Res., 112, D16309, doi:10.1029/2006JD 008294.

Prospero, J. M., P. Ginoux, O. Torres, S. E. Nicholson, and T. E. Gill, 2002: Environmental characterization of global sources of atmospheric soil dust identified with the Nimbus 7 total ozone mapping spectrometer (TOMS) absorbing aerosol product. Rev. Geophys., 40, 1002, doi:10.1029/2000RG 000095.

Randel, W. J., and M. Park, 2006: Deep convective influence on the Asian summer monsoon anticyclone and associated tracer variability observed with Atmospheric Infrared Sounder (AIRS). J. Geophys. Res., 111, D12314, doi:10.1029/2005 JD006490.

Rayner, N. A., D. E. Parker, E. B. Horton, C. K. Folland, L. V. Alexander, D. P. Rowell, E. C. Kent, and A. Kaplan, 2003: Global analyses of sea surface temperature, sea ice, and night marine air temperature since the late nineteenth century. J. Geophys. Res., 108, 4407, doi:10.1029/2002JD002670.

Shao, Y., and H. Lu, 2000: A simple expression for wind erosion threshold friction velocity. J. Geophys. Res., 105, 2243722443.

Shao, Y., M. R. Raupach, and J. F. Leys, 1996: A model for predicting aeolian sand drift and dust entrainment on scales from paddock to region. Aust. J. Soil. Res., 34, 309-342.

Shibata, K., H. Yoshimura, M. Ohizumi, M. Hosaka, and M. Sugi, 1999: A simulation of troposphere, stratosphere and mesosphere with an MRI/JMA98 GCM. Pap. Meteor. Geophys., 50, 15-53.

Slinn, W. G. N., 1984: Precipitation scavenging. Atmospheric Science and Power Production, Vol.DOE/TIC-27601 (DE 84005177), Office of Health and Environmental Research, U.S. Department of Energy, Washington, DC, chapter 11, 466-532.

Sokolik, I. N., and O. B. Toon, 1996: Direct radiative forcing by anthropogenic airborne mineral aerosols. Nature, 381, 681683.

Tanaka, T. Y., and M. Chiba, 2005: Global simulation of dust aerosol with a chemical transport model, MASINGAR. $J$. Meteor. Soc. Japan, 83A, 255-278.

Tanaka, T. Y., and M. Chiba, 2006: A numerical study of the contributions of dust source regions to the global dust budget. Global and Planetary Changes, 52, 88-104, doi:10.1016/ j.gloplacha.2006.02.002.

Uno, I., K. Eguchi, K. Yumimoto, T. Takemura, A. Shimizu, M. Uematsu, Z. Liu, Z. Wang, Y. Hara, and N. Sugimoto, 2009: Asian dust transported one full circuit around the globe. Nature Geoscience, 2, 557-560, doi:10.1038/ngeo583.

Vernier, J.-P., L. W. Thomason, and J. Kar, 2011: CALIPSO detection of an Asian tropopause aerosol layer. Geophys. Res. Lett., 38, L07804, doi:10.1029/2010GL046614.

Wesely, M. L., and B. B. Hicks, 1977: Some factors that affect the deposition rates of sulfur dioxide and similar gases on vegetation. J. Air Pollut. Control Assoc., 27, 1110-1116.

Yumimoto, K., K. Eguchi, I. Uno, T. Takemura, Z. Liu, A. Shimizu, and N. Sugimoto, 2009: An elevated large-scale dust veil from the Taklimakan Desert: Intercontinental transport and three-dimensional structure as captured by CALIPSO and regional and global models. Atmos. Chem. Phys., 9, 8545-8558.

Yumimoto, K., K. Eguchi, I. Uno, T. Takemura, Z. Liu, A. Shimizu, N. Sugimoto, and K. Strawbridge, 2010: Summertime trans-Pacific transport of Asian dust. Geophys. Res. Lett., 37, L18815, doi:10.1029/2010GL043995.

Manuscript received 24 March 2012, accepted 9 August 2012 SOLA: http://www.jstage.jst.go.jp/browse/sola 